\title{
Comparing flexural strength of acrylic processed by three different techniques
}

\author{
Ankit Patel \\ West Virginia University
}

Follow this and additional works at: https://researchrepository.wvu.edu/etd

\section{Recommended Citation}

Patel, Ankit, "Comparing flexural strength of acrylic processed by three different techniques" (2014). Graduate Theses, Dissertations, and Problem Reports. 517.

https://researchrepository.wvu.edu/etd/517

This Thesis is protected by copyright and/or related rights. It has been brought to you by the The Research Repository @ WVU with permission from the rights-holder(s). You are free to use this Thesis in any way that is permitted by the copyright and related rights legislation that applies to your use. For other uses you must obtain permission from the rights-holder(s) directly, unless additional rights are indicated by a Creative Commons license in the record and/ or on the work itself. This Thesis has been accepted for inclusion in WVU Graduate Theses, Dissertations, and Problem Reports collection by an authorized administrator of The Research Repository @ WVU. For more information, please contact researchrepository@mail.wvu.edu. 


\title{
COMPARING FLEXURAL STRENGTH OF ACRYLIC PROCESSED BY THREE DIFFERENT TECHNIQUES
}

\author{
Ankit Patel \\ Thesis Submitted to the \\ School of Dentistry \\ at West Virginia University \\ in partial fulfillment of the requirements for the degree of \\ Masters of Science in \\ Prosthodontics
}

Mark Richards, DDS, Med, FACP, Chair

Mohssen Ghalichebaf, DDS, MS

Michael Bagby, DDS, Ph.D., MS

Matthew Bryington, DMD, MS

Department of Restorative Dentistry

Morgantown, West Virginia

2014

Key words: Acrylic resin, Flexural Strength, Fracture, Injection Molding, Compression Molding, Pressure Pack, CAD/CAM Acrylic, AvaDent

Copyright 2014 [Ankit Patel] 


\title{
ABSTRACT \\ COMPARING FLEXURAL STRENGTH OF ACRYLIC PROCESSED BY THREE DIFFERENT TECHNIQUES
}

\author{
Ankit Patel, DMD
}

Statement of problem: Acrylic resin removable dentures are susceptible to fracture after periods of clinical use. There are many predisposing clinical factors for these denture fractures. Specifically, acrylic resin fractures due to poor flexural strength has historical been a problem with complete denture.

Objective: The purpose of this in vitro study was to measure and compare the flexural strength of denture base acrylic resin processed by three different techniques: Conventional Pressure-Pack (compression molded) method, Injection molded (SR-Ivocap), and Computer Aided Design - Computer Assisted Manufacturing (CAD/CAM) (AvaDent ${ }^{\mathrm{TM}}$ Digital Dentures).

Methods: A total of 45 specimens (64 mm X $10 \mathrm{~mm} \mathrm{X}$ varying thicknesses of $2 \mathrm{~mm}, 3 \mathrm{~mm}$, and $5 \mathrm{~mm}$ ) were fabricated, 15 for each of the three materials being tested. Specimens were tested according to the American Society for Testing and Materials (ASTM) standard D79003 for flexural strength of reinforced plastics. The specimens were loaded until fracture or 15 $\mathrm{mm}$ of displacement on a three-point bending test machine (Instron® Model 5565 Universal Testing Machine).

Results: Data from this flexural strength study indicates that SR- Ivocap Injection Mold technique showed a higher flexural strength than CAD/CAM Avadent and Pressure-pack. When a $3 \mathrm{~mm}$ specimen was considered, statistically significant difference was apparent between Injection mold and the other two techniques (CAD/CAM and Pressure-Pack).

Conclusions: The flexural strength test is significantly useful in comparing denture base materials in which stress of this type is applied to the denture during mastication. The results from flexural test indicated that the differences observed can be attributed to the polymer constituents and to the method of polymerization. SR-Ivocap Injection Molding may prove to be more advantageous than CAD/CAM AvaDent ${ }^{\mathrm{TM}}$ and Pressure-Pack. 


\section{$\underline{\text { Dedication }}$}

To my family and friends, without whom this research would not have been possible.

Thank you for all your tremendous support and encouragement. I cannot imagine surviving this Prosthodontics residency without all of you by my side. 


\section{Acknowledgements}

Dr. Mark Richards, you are by far the greatest mentor a student can ask for. I am indebted to you for teaching me everything I know in the world of dentistry and world of maker's mark. I will absolutely be your computer guy in Florida when I come there.

Dr. Matthew Bryington, you have been more help than you think this past year. You have not only opened up my eyes to new treatment modalities but, also taught me tremendous amount about life in general. Thank you very much and I wish I could have learned more from you. We are going to be lifelong friends and you will absolutely be my lifelong mentor.

Dr. Mohssen Ghalichebaf, you are no less than a father to me. I have learned so much about prosthodontics and life from you. I will truly miss you. You have taken me under your wing and taught me so many life lessons that I have lost track of them. I will make sure that you will write a book of all your proverbs and publish it because it would be by far a best seller.

Dr. Michael Bagby, I have never met someone so enthusiastic and knowledgeable about dental materials. I really appreciate you kickstarting my research and helping me every step of the way. I know I will spend time with you in Chicago in the future and keep learning from you. Thank you very much. 


\section{Table of Contents}

COMPARING FLEXURAL STRENGTH OF ACRYLIC PROCESSED BY THREE

DIFFERENT TECHNIQUES.................................................................... 1

Abstract ......................................................................................................................................... 2

Dedication .............................................................................................................................. 3

Acknowledgements .................................................................................................................... 4

List of Figures............................................................................................................................................ 5

List of Tables ............................................................................................................................. 6

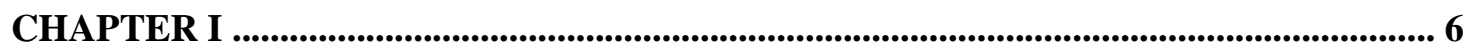

Introduction ......................................................................................................................................... 6

Statement of the Problem ................................................................................................... 7

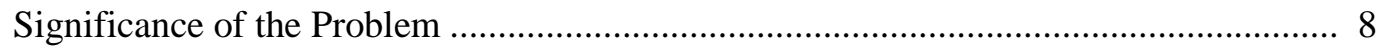

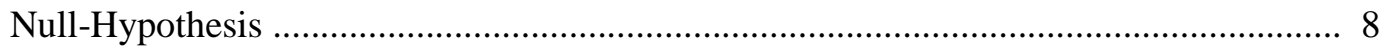

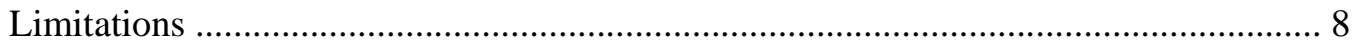

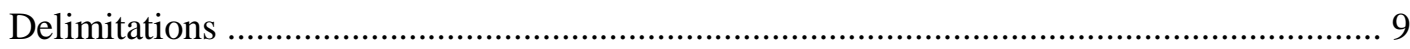

Chapter II .......................................................................................................................................... 9

Review of Literature ...................................................................................................................... 9

Chapter III ................................................................................................................................................ 17

Materials and Methods ............................................................................................................ 17

Chapter IV ....................................................................................................................... 26

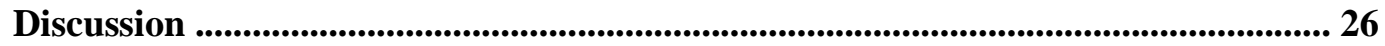

Chapter V ..................................................................................................................... 37

Discussion ............................................................................................................................................. 37

References ............................................................................................................................... 39 


\section{CHAPTER I}

\section{$\underline{\text { Introduction }}$}

The material of choice for complete dentures is polymethylmethacrylate (PMMA). Its low cost, ease of application and polishing, and reliance on simple processing equipment have made it a preferred base material; however, this material presents limitations, particularly in terms of transverse and impact strength (Mang 2005).

Acrylic resin removable dentures are susceptible to fracture after periods of clinical use. There are many predisposing clinical factors for denture fractures (Beyli 1981). Information about the mechanical properties of acrylic materials could help with the understanding and improvement of denture fractures (Gurbuz 2010). Within the last decade, this technology has been extrapolated to the field of Removable Prosthodontics. It has become commercially available for the fabrication of complete dentures through AvaDent ${ }^{\mathrm{TM}}$ digital dentures (Kattadiyil 2013). AvaDent ${ }^{\mathrm{TM}}$ offers the option of providing the denture base in Dentsply Lucitone 199, Ivoclar Probase Hot, or Keystone Diamond D. CAD/CAM technology is used for creating denture base by milling blocks of pre-polymerized acrylic and eliminate the possibility of any post-processing shrinkage or distortion (Kattadiyil 2013). Additionally, AvaDent ${ }^{\mathrm{TM}}$ claims that there are no porosities in the milled denture base from a block (AvaDent digital dentures 2013).

Computer Aided Design - Computer Aided Manufacturing (CAD/CAM) technology has made tremendous strides in the field of dentistry. CAD software acquires the image into the computer through a digital impression and enables the dentist or lab technician to design the restoration digitally. CAM hardware receives the data and directs the milling process. This technology is used to design and fabricate numerous dental restorations such as crowns, inlays, onlays, veneers, fixed dental prostheses, and dental implant abutments. 
Many different processing techniques have been developed to improve and simplify the polymerization technique and to reduce denture production time. Pressure-Pack, Injection Mold, Microwave, and as described above, CAD/CAM are some of the many (Zappini 2003). There are many studies in the literature that compare mechanical properties of the acrylic processed by pressure pack, microwave, and injection molded (Jadhav 2013, Machado 2007, Mang 2005, Zappini 2003). Zappini et al. demonstrated Injection Mold technique had significantly higher fracture resistance than microwave (Zappini 2003).

The purpose of this in vitro study was to compare the flexural strength of denture base acrylic resin (PMMA) processed by three different techniques: Conventional pressure-pack (compression molded) method, Injection molded (SR-Ivocap), and CAD/CAM (AvaDent ${ }^{\mathrm{TM}}$ Digital Dentures).

Flexural strength was selected as the unit of comparison because it is the value that has been reported most commonly in dental literature. The flexural strength is significant because it evaluates the rigidity of the material to withstand stress without fracture, which in turn affects the integrity of the supporting ridge and tissues, as well as the accuracy of denture fit (Raut 2013).

\section{Statement of the Problem}

Despite the wide use and popularity of CAD/CAM dentures, there has not been a study in the dental literature that compares flexural strength of acrylic denture processed by CAD/CAM, with Injection Molded and Pressure-Pack.

\section{Significance of the Problem}


CAD/CAM dentures are used daily and becoming increasingly popular with relatively limited evidence. Since the introduction of CAD/CAM acrylic, there have been several claims by the manufacturer, AvaDent ${ }^{\mathrm{TM}}$, about its elimination of porosities and shrinkage. There are claims that CAD/CAM dentures provide better fit of the prosthesis (Kattadiyil 2013). Questions rise about its strength and this study provides a test of its flexural strength.

\section{Null Hypothesis}

No statistically significant difference between the flexural strengths of acrylic will be seen regardless of manufacturing technique: CAD/CAM, Injection Mold, and Pressure-Pack processed acrylic.

\section{Limitations}

There is a small specimen size that is subjected to the three-point bending test. This is an in vitro study and does not directly relate to a particular clinical situation. This study does not examine the morphology and microstructure of fractured acrylic specimens by Scanning Electron Microscopic (SEM) analysis. All specimens prepared have a slight variation in size and to keep consistent dimensions of the specimens is very difficult. The specimens prepared are rectangular in shape rather than a complex denture design. The specimens were not aged in an aqueous solution and subjected to a cyclic load to fatigue test, which would be more suitable to simulate the clinical failure mechanism (Wiskott 1995).

\section{Delimitations}

There are a total of 45 specimens prepared of which 15 were allotted to each of the three polymerization techniques. Out of those 15 , five of the specimens were prepared with $2 \mathrm{~mm}$ 
thickness, five with $3 \mathrm{~mm}$ thickness, and five with $5 \mathrm{~mm}$ thickness. This in vitro study evaluates how much flexural force these specimens can withstand before fracturing. In clinical scenarios involving heavy masticatory forces, the material with the higher flexural strength and more rigidity can be better suited. Although this study provides information about flexural strength measurements, SEM analysis can be performed as a follow up study to allow for descriptive analysis of porosities, craze lines, orientation of PMMA fibers, etc. To keep dimensions consistent, any difference in dimension greater than $0.2 \mathrm{~mm}$ with respect to length, width, or thickness, was discarded.

\section{CHAPTER II}

\section{$\underline{\text { Review of Literature }}$}

Up until the mid-19th century, denture bases were predominantly made from animal materials (Wall 1955). The materials used included bovine bones and teeth of mammals, for instance ivory from elephants and walruses (Wall 1955). From around the mid-18th century onwards, denture bases were also fabricated from porcelain and precious metals (Wall 1955). Wood has also used for years to fabricate dentures. It was readily available, relatively inexpensive, and can be carved into a desired shape however, not only was it esthetically displeasing but also warped and cracked in the presence of moisture (Zakhari 1976).

After Goodyear had invented the vulcanization process in 1851, rubber was used to fabricate dentures (Vulcanite Dentures). This marked a new era in dental prosthetics, because rubber was rather easy to process and quite stable in the oral environment.

After the introduction of the transparent material polymethylmethacrylate (PMMA) acrylic resin during the 1930s, the material was soon used in dental prosthetics. Acrylic resin has 
a wide application in dentistry as bases for Removable Dental Prostheses (RDP), tooth or implant retained Overdentures, orthodontic appliances, stents, surgical guides, and for provisional crowns (Al-Rifaiy 2010). Acrylic resin has also become the most commonly used material for fabricating complete dentures (Zarb 2004).

PMMA polymers were first introduced as a denture base material in 1937 (Craig 2002). Since its inception, acrylic resin denture base material has been studied extensively for its physical, chemical, and mechanical properties.

The advantages of PMMA include excellent esthetic properties, ease of manipulation, low water sorption, low solubility, lack of toxicity, and facility of repair (Parvizi 2004). On the other hand, despite its widespread popularity, PMMA is not without its shortcomings as a denture base material. It doesn't exhibit all requirements of an ideal denture base material (Zarb 2004). Zarb describes an ideal denture base material to fulfill all of the following requirements: natural appearance, easy to manipulate, high strength, low density, dimensionally stable, lack of toxicity and taste, resistance to absorption of oral fluid, resistance to bacterial growth, ease of repair, cheap, and good shelf life (Zarb 2004). PMMA can discolor and is low in strength, resulting in fractures over the years. Fracture of acrylic resin dentures is an unresolved problem in Removable Prosthodontics (Beyli 1981). It occurs quite frequently because of the fatigue and chemical degradation of the base material (Raut 2013). Moreover, heavy masticatory forces have a deforming effect during function and any factor that increases deformation or increases changes in stress distribution may lead to denture fracture (Beyli 1981, Gurbuz 2010). To reduce the incidence of fracture of denture bases, a good processing technique that reduces or eliminates residual stress within the denture and prevents surface defects is essential. Many authors stated 
that mechanical properties of PMMA varied depending on the polymerization technique (Nogeuira 1999, Raut 2013, Zappini 2003).

The basis for the processing of an MMA/PMMA-based denture base resin is a liquid (main component: MMA (methylmethacrylate monomer) and a resin powder (main component: PMMA). Mixing these two components induces a swelling and dissolution process that produces a dough-like and kneadable substance (Yannikakis 2002). Denture base materials are polymerized in several steps. The initiator, which is brought into the mixture as a result of the dissolution process, is split into radicals either by heat (heat curing polymer) or by the chemical reaction with the catalyst (self-curing polymer) (Craig 2002). The initiator radical interferes with the electron system of the double bond of the monomer molecule and splits this bond. After the addition to the monomer molecule, a chain radical is formed. This chain radical, in turn, attacks another monomer molecule and links with it. This process is repeated uncountable times, until a sufficient number of monomer molecules is no longer available. In this way, many chain molecules are created, firstly through chain growth and secondly through the combination of chain radicals resulting in a dense network of macromolecules (Craig 2002).

PMMA goes through a deformational change during processing. It undergoes thermal expansion during heating, contraction during cooling, and shrinkage during polymerization. Polymerization shrinkage has two main effects: Shrinkage distorts the palate of maxillary denture resulting in an inaccurate fit to the supporting tissues (Barsoum 1968) and affects the position of the teeth on maxillary and mandibular dentures thus affecting the final occlusion of dentures (Baemmert 1990). Woelfel and Paffenbarger have shown that the greatest distortion occurs in cross arch region when denture is deflasked (Woelfel 1960). Becker et al. stated that the characteristics of heating and cooling produce an internal stress that is released during the 
deflasking step creating unavoidable dimensional changes and denture base deformation (Becker 1977). These dimensional changes are also attributed to differences in coefficient of thermal expansion between the stone cast and acrylic resin (Skinner 1943). In general, heat polymerized acrylic resin dentures experience a linear shrinkage of $0.3-0.5 \%$ during processing and subsequently show a linear expansion of $0.1-0.2 \%$ upon immersion in water thus, rendering the total linear shrinkage of 0.1-0.4\%. (Craig 2002).

Alternative materials to PMMA have been used for denture base fabrication to overcome the undesirable problem of polymerization shrinkage. A visible light polymerized resin was commercially introduced (Eclipse; Dentsply International Inc. York, Pa.) (Machado 2007). Chemical composition of the material, according to the manufacturer, is based on Urethane Dimethylmethacrylate (UDM) and photoinitiation. Three dimensional denture base processing study by Artopoulus et al. showed that UDMA has significantly more processing deformation than PMMA (Artopoulus 2013).

Numerous different PMMA processing techniques including Pressure-Pack, Injection Mold, Microwave, and CAD/CAM are made available today. Many studies have demonstrated that Pressure-Pack technique leads to increased shrinkage and an increase in overall occlusal vertical dimension (Nogueira 1999, Keenan 2003). To overcome the problems associated with Pressure-Pack technique resulted in development of a continuous injection system. Introduced in 1942 by Pryor, this technique allows for directional control of the polymerization process through the flask design. A constant flow of new material under pressure compensates for the polymerization shrinkage (Pryor 1942). Many reports have shown significantly smaller incisal pin opening for complete dentures produced by an injection system compared with complete 
dentures produced by Pressure-Pack technique (Keenan 2003, Nogueira 1999, Strohaver 1989, Sykora 1990).

A study by Nogueira and colleagues concluded that: 1. Injection molding produced a significantly smaller incisal pin opening when compared with standard Pressure-Pack technique. 2. Injection molding system was the more accurate method. 3. There was no appreciable difference in laboratory working time between injection and pressure-pack techniques. If anything, injection molding would save time in construction of a denture because of the smaller incisal pin opening and reduction in time for post-processing adjustments (Nogueira 1999).

During lab processing of complete denture, an increase of occlusal vertical dimension (OVD) occurs. An increase in OVD is an important clinical consideration that is related to essential characteristics of materials and techniques (Strohaver 1989). Nogueira et al. showed that dentures processed with conventional pressure packed technique had $1.16 \mathrm{~mm}$ of incisal pin opening compared with those processed with Injection molding had $0.31 \mathrm{~mm}$ (Nogueira 1999). Moreover, although clinically significant incisal pin opening may occur, Pressure-Pack technique is still considered acceptable (Nogueira 1999).

Various injection molded denture base materials and brand names are commercially available each claiming to produce a more accurate denture base. Success system (Dentsply International Inc. York, Pa.) is one of the many systems that allows the use of an injectable PMMA and produces dentures that require few, if any, adjustments in lab. Material recommended by manufacture with this injection system is PMMA Lucitone 199 (Dentsply International Inc.) which is mixed in a conventional manner and put in a special detachable plastic cartridge for the injection procedures. 
In 1970, Ivoclar introduced an injection molding system that used acrylic resin modified for injection molding process. The SR - Ivocap (Ivoclar Vivadent AG, Schaan, Liechtenstein) is an injectable PMMA recommended by Ivoclar to be used with their Injection system. Zappini et al. demonstrated in an in vitro study that Ivocap had significantly higher fracture resistance and advised to use this material in complete denture fabrication (Zappini 2003). There have been various studies carried out on this material in the dental literature that supports the claim that SRIvocap system has less linear dimensional changes than conventional Pressure-Pack (Anderson 1988, Garfunkel 1983).

These injection systems still require flasking, deflasking, and tedious laboratory work time. The adapting technology used in the fabrication of fixed prosthodontics to complete dentures has made the need for investing and flasking obsolete. CAD/CAM technology has been used for fabrication of crowns, inlays, fixed bridges, implant abutments, and other prostheses (Miyazaki 2009). It can either involve additive manufacturing (rapid prototyping) or subtractive manufacturing (computerized numerical control (CNC) machining). Additive manufacturing or 3D printing uses images from digital file to create an object by laying down successive layers of chosen material. Subtractive manufacturing uses images from digital file to create an object by machining (cutting/milling) to physically remove material to achieve desired geometry.

In the world of Prosthodontics, subtractive CAD/CAM procedures are widely used (The glossary of prosthodontic terms, 2005). Maeda et al. has been credited with the first published scientific report in English on concept of using CAD to fabricate complete dentures (Maeda 1994). Their report described the fabrication of complete denture from photopolymerized composite resin material with rapid prototyping technology (Maeda 1994). This was followed by a report in 1997 from another Japanese group, Kawahata et al., who explored the concept of 
digitally duplicating existing dentures and milling them by using a CNC milling machine (Kawahata 1997).

Recently, CAD/CAM technology has become commercially available for fabrication of complete dentures through the introduction of commercially available products called AvaDent $^{\mathrm{TM}}$ digital dentures (Global Dental Science LLC. Scottsdale, AZ) and Dentca CAD/CAM (Dentca Inc., LA).

Bidra et al. prepared a very detailed systematic review and analysis of existing literature pertaining to computer aided technology for fabricating complete dentures. He discussed the limitations and disadvantages of current CAD/CAM commercial systems. He mentioned that optimal assessment of OVD, Jaw relation records, lip support, and maxillary incisal edge position is very challenging (Bidra 2013). In addition, establishing the mandibular occlusal plane is very difficult. A major drawback of currently available systems is a lack for clinicians and patients to evaluate a trial denture intraorally. This disadvantage has been partially addressed by one of the manufacturers (AvaDent ${ }^{\mathrm{TM}}$ ) but additional costs are involved (Bidra 2013).

There are several expected advantages of current CAD/CAM denture over other commercially available PMMA polymerization methods. Denture can be fabricated in as few as two clinical visits which benefits both patients and clinicians (Kattadiyil 2013). Optimal occlusal scheme can be developed with only minimal adjustments and a denture can be easily duplicated as the CAD files are digitally stored. Kattadiyil claims that denture fit is better as the denture base is milled from prepolymerized block of acrylic resin. Moreover, a further study showed that CAD/CAM acrylic has minimal porosities which mean less chance of microorganisms such as Candida Albicans (Munoz 2013). CAD/CAM denture base can be used 
to proceed with subsequent steps of Jaw relation records, trial placement, and denture processing using conventional methods. Although this CAD/CAM technology is being widely used today for fabricating complete dentures, there has yet to be a study that compares this CAD/CAM acrylic resin with acrylic resin processed by injection mold and pressure-pack.

The purpose of this study was to measure and compare the flexural strength of denture base acrylic resin processed by three different techniques: Conventional Pressure-Pack (compression molded) method, Injection molded (SR-Ivocap), and Computer Aided Design Computer Assisted Manufacturing (CAD/CAM) (AvaDent ${ }^{\mathrm{TM}}$ Digital Dentures).

\section{CHAPTER III}

\section{Materials and Methods}

This in vitro experiment was performed to measure and compare the flexural strength of denture base acrylic resin processed by three different techniques: conventional Pressure-Pack (compression molded) method, Injection molded (SR-Ivocap), and CAD/CAM (AvaDent ${ }^{\mathrm{TM}}$ Digital Dentures).

The specific denture resins examined were Lucitone 199 (Dentsply International Inc.), SR-Ivocap (Ivoclar Vivadent AG, Schaan, Liechtenstein), and Pre-polymerized Lucitone 199 (AvaDent $^{\mathrm{TM}}$ Global Dental Sciences LLC. Scottsdale, AZ) (Table 1). Each denture base material was tested for flexural strength according to ISO 1567 standards. A total of 45 specimens of dimension $64 \mathrm{~mm} \times 10 \mathrm{~mm} \times$ varying thickness of $2 \mathrm{~mm}, 3 \mathrm{~mm}$, and $5 \mathrm{~mm}$ were prepared (Figure 1) (ISO Standards). The accuracy of the dimensions was verified at three different locations using a plastic ruler. The specimens were divided into three groups:

Group 1 - CAD/CAM acrylic specimens (15 specimens with three varying thicknesses) 
Group 2 - Injection Molded acrylic specimens (15 specimens with three varying thicknesses)

Group 3 - Pressure-Pack acrylic specimens (15 specimens with three varying thicknesses)

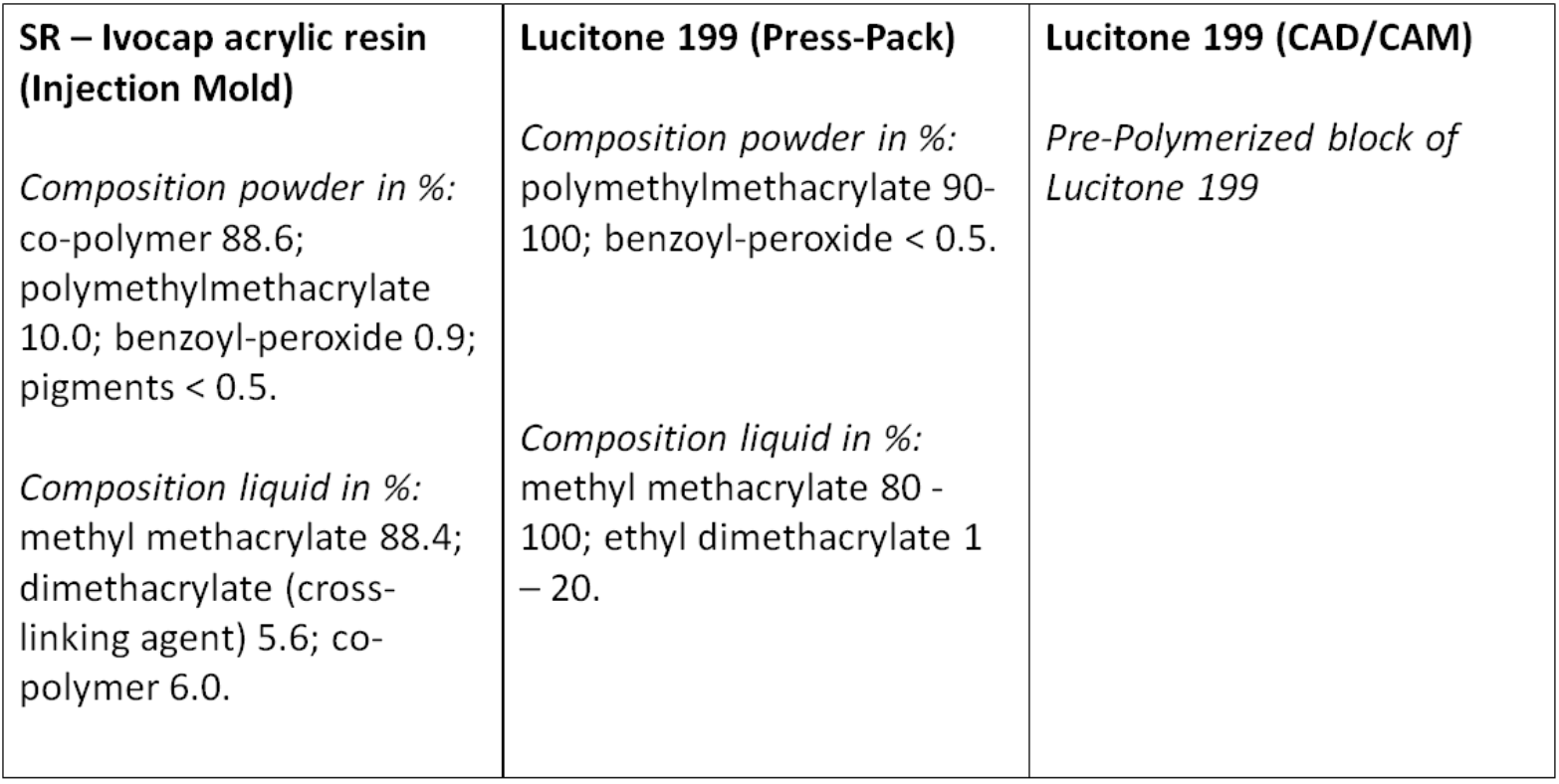

Table 1: Composition of Acrylic Resins Examined

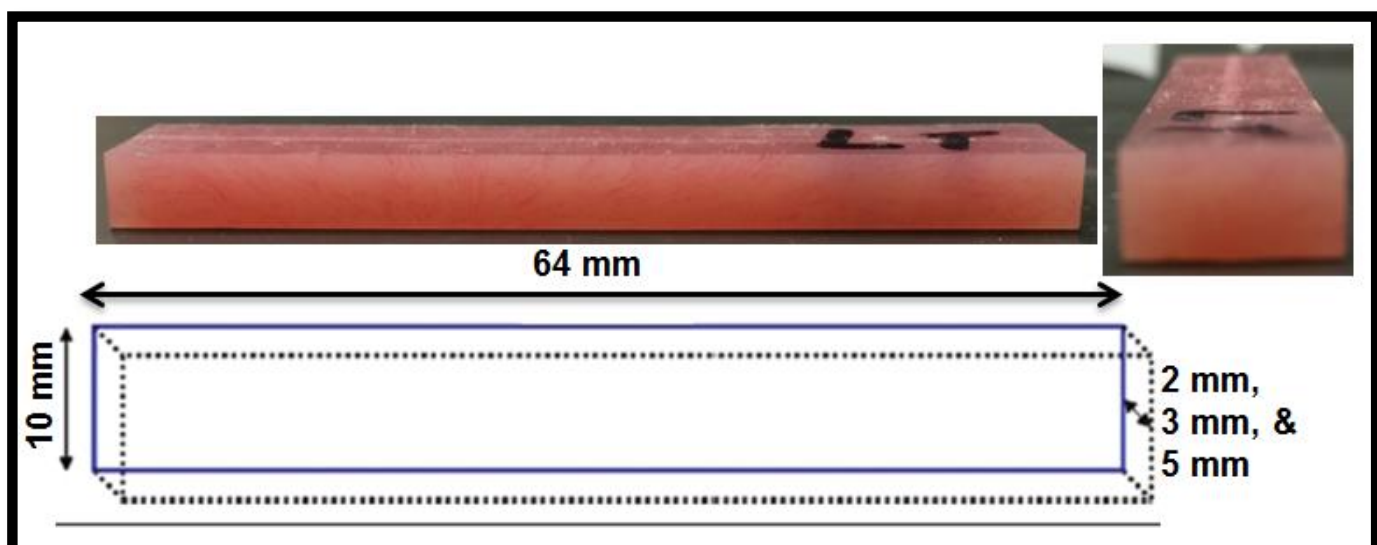

Figure 1 : Representation of specimen dimensions

\section{Preparation of experimental specimens}

Preparation of CAD/CAM AvaDent ${ }^{T M}$ acrylic specimens 
15 experimental specimens were milled from a prepolymerized (cured) block of PMMA acrylic block to the desired sizes. The prepolymerized block of acrylic was Lucitone 199. Five specimens were $2 \mathrm{~mm}$ in thickness, five were $3 \mathrm{~mm}$ in thickness, and five were $5 \mathrm{~mm}$ in thickness. These specimens were milled out of a block of prepolymerized block of acrylic by AvaDent ${ }^{\mathrm{TM}}$ with CAD/CAM technology (Figure 4).

\section{Preparation of Injection molded acrylic specimens}

Figure 2 shows the materials and equipment of SR-Ivocap injection system. Sil-tech Super Putty (Ivoclar Vivadent AG) was used to duplicate the specimens prepared by CAD/CAM. SR Ivocap Injection System (Ivoclar Vivadent AG) instructions were followed for flasking and polymerization. Type III dental stone was used for investment. Ivocap Acrylic capsule contains $20 \mathrm{~g}$ polymer and $30 \mathrm{ml}$ monomer. Mixing was immediately started following the addition of the monomer to the polymer ( $5 \mathrm{~min}$ in the Cap Vibrator). Then, the flask was completely inserted into the clamping frame. 3 tons / $6000 \mathrm{lbs}$ pressure was applied to the clamping frame with the flask in a hydraulic press (corresponds to about 80 bar / 1133 psi hydraulic pressure). Pressure apparatus was connected to the compressed air supply ( $85 \mathrm{psi})$ then, the acrylic was injected. The SR Ivocap assembly was then placed in a polymerization bath of $100^{\circ} \mathrm{C}$ temperature. The specimens were polymerized for a total of 35 minutes from the start of the water boiling. The

specimens were then allowed to cool for the first 20 minutes under pressure, and then just the frame with clamp were immersed under cool running water for the next 10 minutes. The specimen were recovered after deflasking and then finished and polished (Figure 5). 


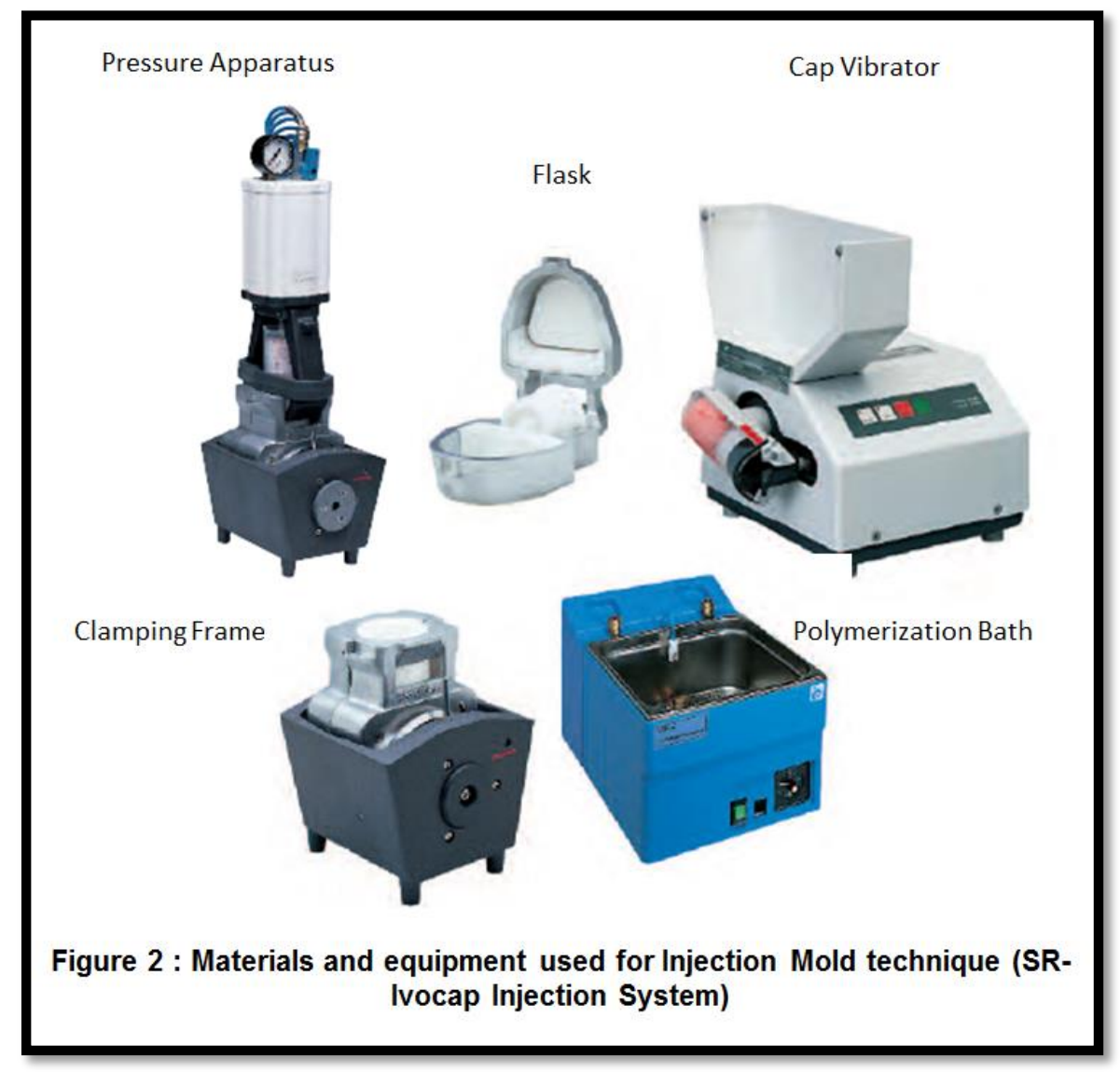

\section{Preparation of Pressure-Pack acrylic specimens}

Figure 3 shows the materials and equipment used for Pressure-Pack technique. Sil-tech Super Putty (Ivoclar Vivadent AG) was used to duplicate the specimens prepared by CAD/CAM. Type III dental stone was used for investment. 1 unit of polymer $(21 \mathrm{~g} / 32 \mathrm{cc})$ was added to $10 \mathrm{ml}$ of monomer in a mixing jar. This was stirred sufficiently for 15 seconds to assure wetting of all the powder particles. Mixing jar was covered with a Densilk plastic separating sheet and the lid was placed on top of that. Packing consistency (doughy stage) was reached after 8 minutes and the acrylic was packed in a warm flask. The material was condensed well to adapt to the dimensions created by the Sil-tech Super Putty. The flasks were adapted well together and compressed. Excess resin was removed and close locked flask was submerged in water at $165^{\circ} \mathrm{F}$ for 9 hours. The flask was allowed to bench cool clamped together for 30 minutes and then 
immersed in cool water for 15 minutes before deflasking. The specimens were finished and polished after being recovered (Figure 6).
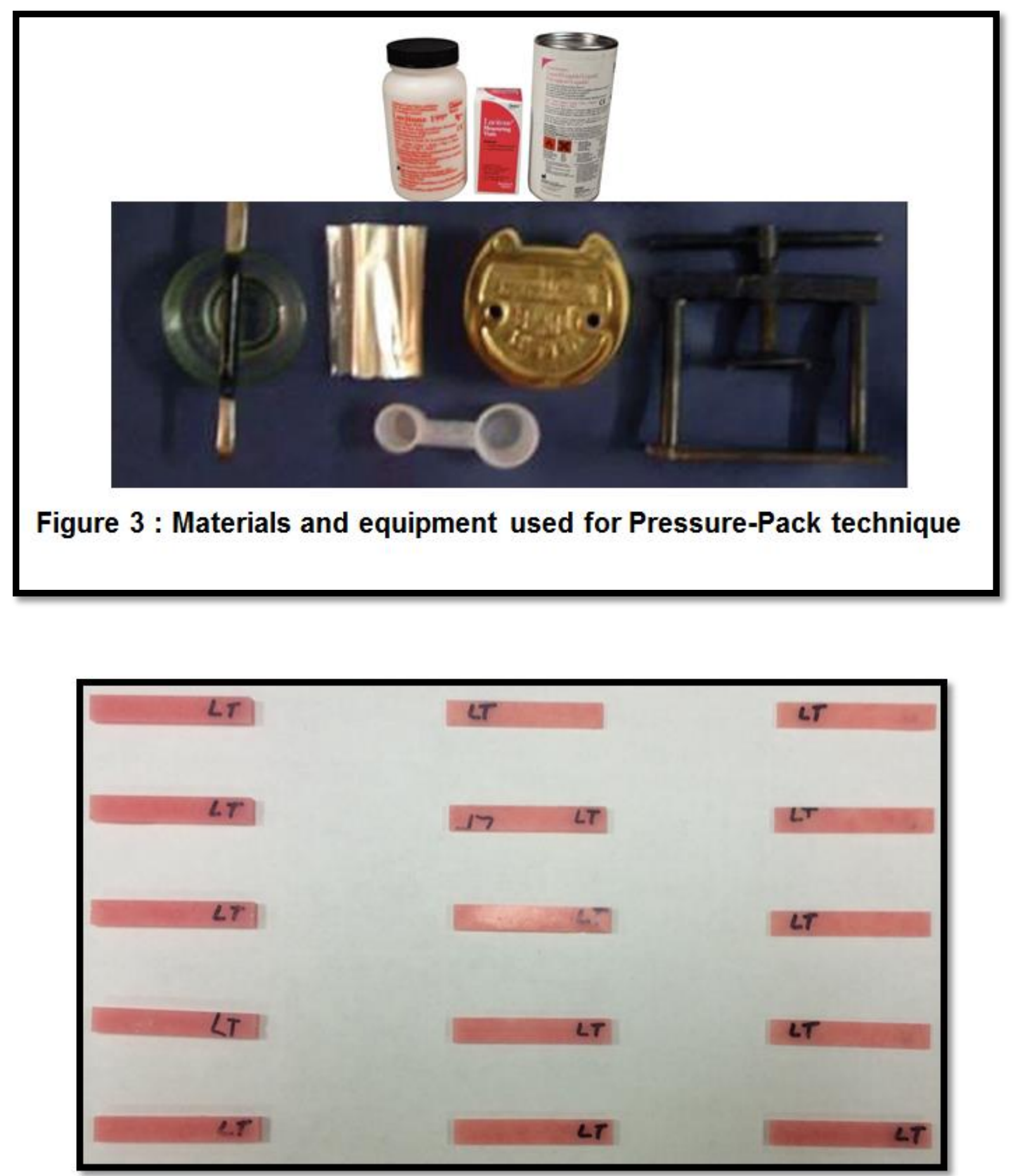

Figure 4: CAD/CAM Acrylic Samples 


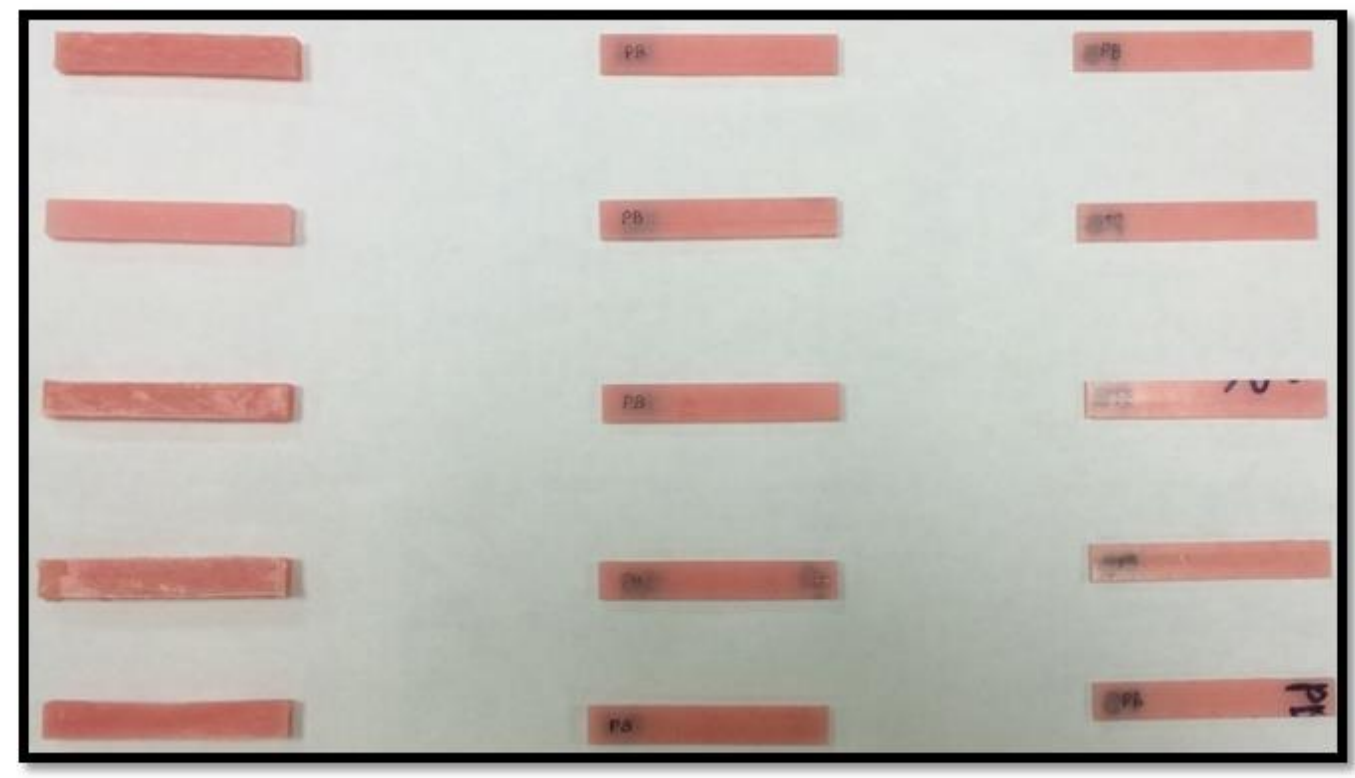

Figure 5: Injection Molded Acrylic Samples

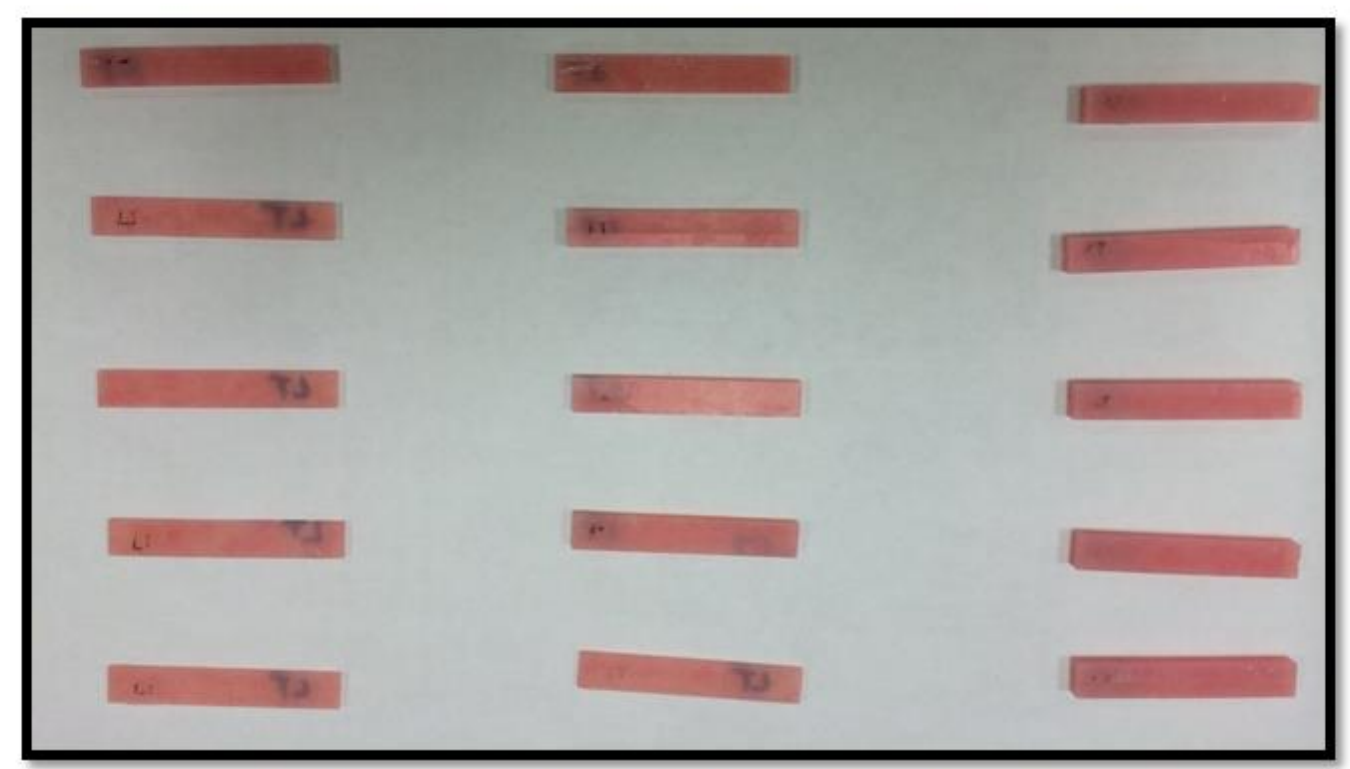

Figure 6: Pressure Packed Acrylic Samples

Flexural strength test 
Flexural strength testing was performed using a three-point bending test machine (Instron® Model 5565 Universal Testing Machine. Norwood, MA) (Figure 7). A design was used whereby the simple specimen beam was centrally loaded at a cross-head speed of $5 \mathrm{~mm} / \mathrm{min}$ over the center of two support wedges span set at $50 \mathrm{~mm}$ (Figure 8) (Raut 2013). The loading wedge was brought down at a crosshead. The specimens were deflected until fracture occurred or $15 \mathrm{~mm}$ of displacement (Raut 2013). The force required for the fracture was recorded and the stress was calculated by means of the following equation (ASTM 2005):

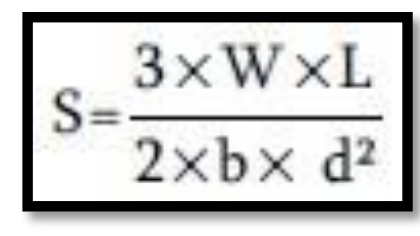

where

$\mathrm{S}=$ flexural strength

$\mathrm{W}=$ load at fracture $(\mathrm{N})$

$\mathrm{L}=$ distance between supporting wedges $(50.00 \mathrm{~mm})$ (Figure 8)

$\mathrm{b}=$ width of the specimen $(\mathrm{mm})(10 \mathrm{~mm})$

$\mathrm{d}=$ thickness of the specimen $(\mathrm{mm})(2,3$, or $5 \mathrm{~mm})$

The mean flexural strength values were calculated for each group. The data were analyzed by means of One Way Analysis of Variance test (ANOVA), followed by post hoc Tukey - Kramer honest significant difference (HSD) and Least Significant Difference (LSD) multiple comparison tests. Statistical significance level was set at $P<0.05$. 


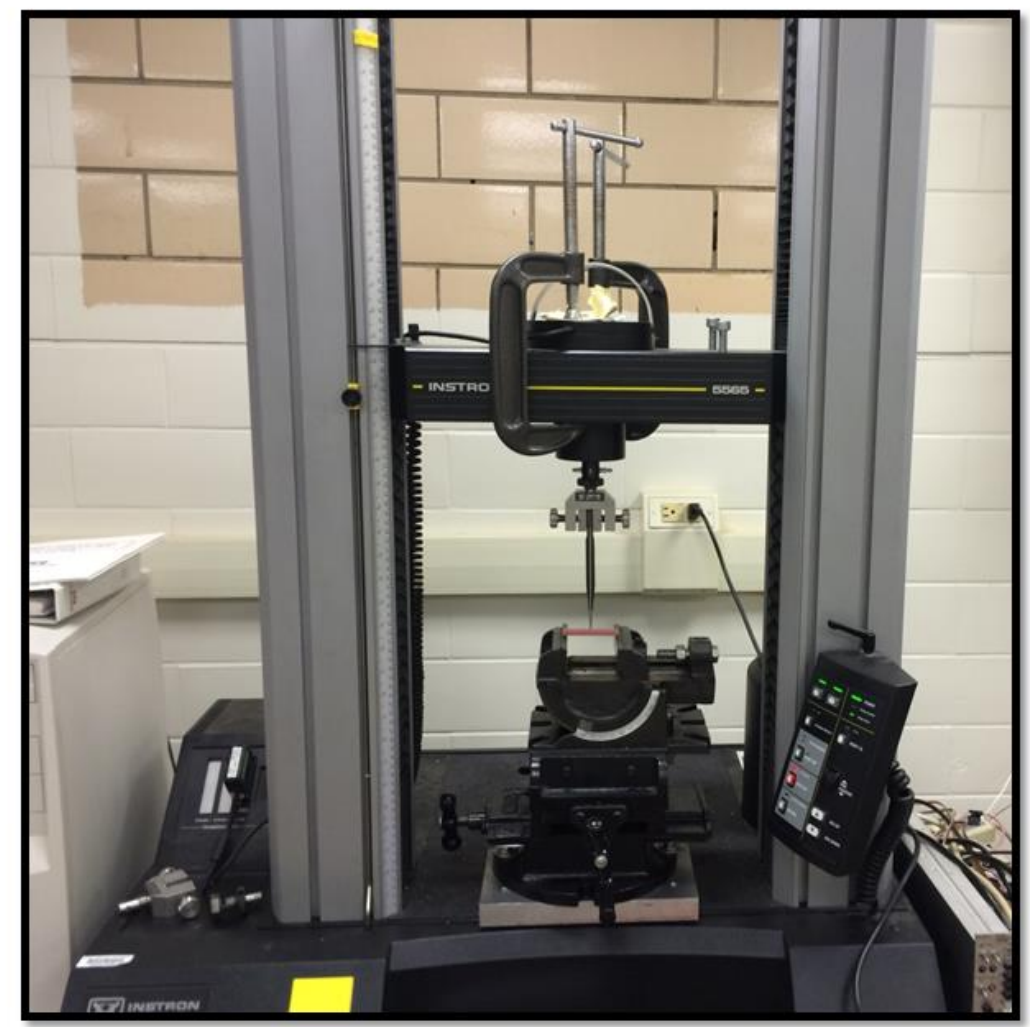

Figure 7: Specimen in place for the three-point bending flexural strength test (Instron ${ }^{\circledR}$ Model 5565 Universal Testing Machine)

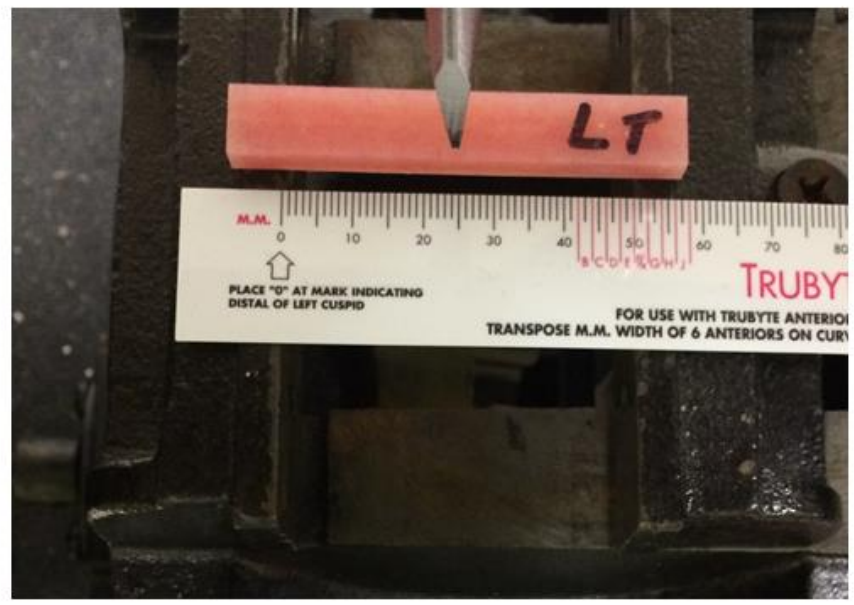

Figure 8: Specimen in place for the three-point bending flexural strength test showing $50 \mathrm{~mm}$ distance between the supporting wedges 


\section{CHAPTER IV}

\section{$\underline{\text { RESULTS }}$}

Table 2 summarizes the results of the determined flexural strength for each group of acrylic and thicknesses. The mean flexural strength values and standard deviations were calculated for each group. It must be noted that the $2 \mathrm{~mm}$ Pressure-Packed specimen flexed and did not fracture at the set limit (arbitrarily set to $15 \mathrm{~mm}$ of displacement) (Raut 2013)

\begin{tabular}{|c|c|c|c|c|c|c|c|c|c|}
\hline Acrylic/Technique & & Injection Mold & & & CAD/CAM & & $\hbar$ & Pressure - Pack & \\
\hline Thickness & $2 \mathrm{~mm}$ & $3 \mathrm{~mm}$ & $5 \mathrm{~mm}$ & $2 \mathrm{~mm}$ & $3 \mathrm{~mm}$ & $5 \mathrm{~mm}$ & $2 \mathrm{~mm}$ & $3 \mathrm{~mm}$ & $5 \mathrm{~mm}$ \\
\hline Specimen 1 (N) & 43.2 & 102.8 & 360.2 & 39.2 & 78.7 & 309.1 & 22 & 76.6 & 361.8 \\
\hline Specimen 2 (N) & 38.6 & 104 & 357.3 & 41.3 & 80 & 311.1 & 23 & 81.6 & 277.9 \\
\hline Specimen $3(\mathrm{~N})$ & 40.6 & 107 & 322.5 & 38.5 & 97.8 & 306.5 & 23.6 & 78.3 & 185.9 \\
\hline Specimen 4 (N) & 41.4 & 106.8 & 326 & 42.2 & 94.5 & 319.9 & 21.8 & 82.8 & 237.6 \\
\hline Specimen $5(\mathrm{~N})$ & 42 & 108.6 & 355.1 & 41.2 & 86 & 256.5 & 25.6 & 73 & 226.8 \\
\hline Mean & 41.2 & 105.8 & 344.2 & 40.5 & 87.4 & 300.6 & 23.2 & 78.5 & 258.0 \\
\hline Std Deviation & 1.72 & 2.37 & 18.36 & 1.56 & 8.53 & 25.17 & 1.53 & 3.94 & 66.63 \\
\hline Flexural strength (Mpa) & 77.3 & 88.8 & 103.2 & 75.9 & 72.8 & 90.8 & & 65.3 & 77.4 \\
\hline
\end{tabular}

Table 2 : Raw data, mean load (N), Flexural Strength (MPa) and standard deviation for each group $\hbar=2 \mathrm{~mm}$ Pressure-Packed specimen flexed to a displacement limit set forth $(15 \mathrm{~mm})$ and did not fracture

Graph 1 shows an example of a line curve that the computer connected to the Instron ${ }^{\circledR}$ machine was recording. It represents a CAD/CAM $3 \mathrm{~mm}$ acrylic specimen and shows how much the specimen is flexed until it reached a yield point and fractured at $4.6 \mathrm{~mm}$ of displacement and $86 \mathrm{~N}$ of Load.

Figure 9 depicts the displacement and flexure of a specimen. Figure 10 shows a $2 \mathrm{~mm}$ specimen prepared from Pressure Packed technique that did not fracture and flexed up to $15 \mathrm{~mm}$ displacement limit. 

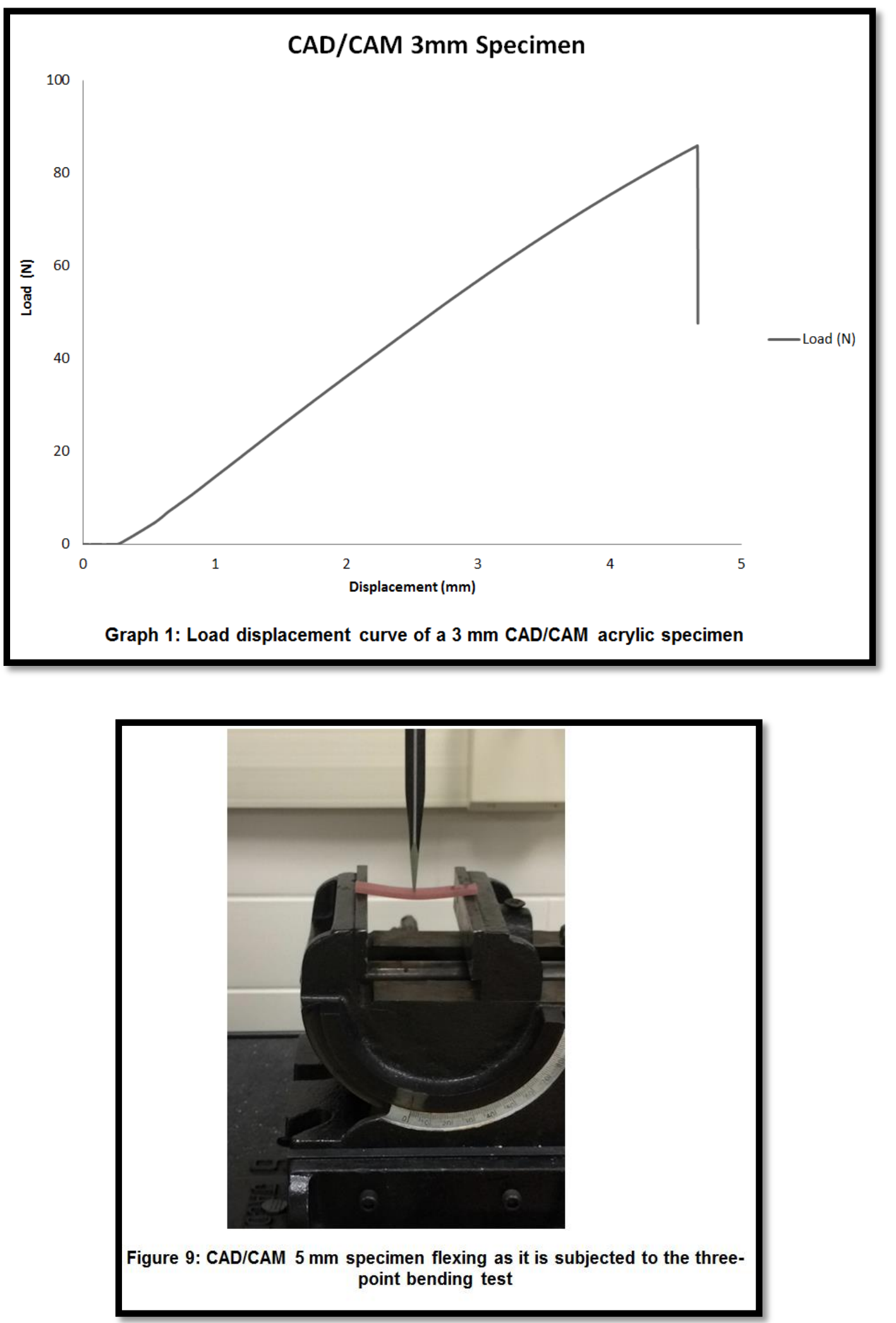


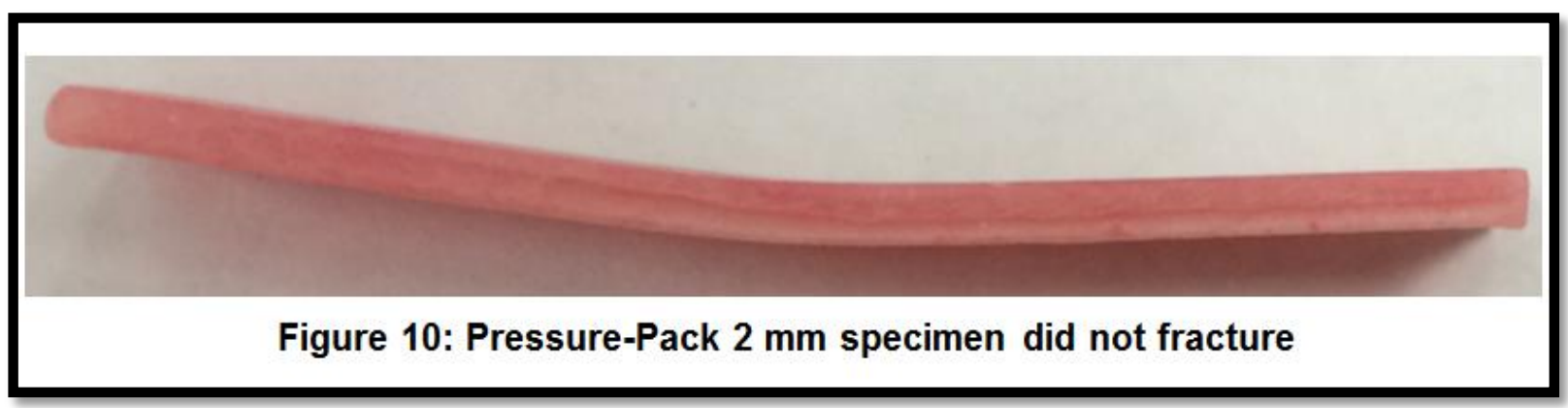

One way AOVA analysis for $2 \mathrm{~mm}$ thick specimens denoted no significant difference.

For $3 \mathrm{~mm}$ specimen, there was a significant difference with $\mathrm{p}<0.0001$. For $4 \mathrm{~mm}$ specimen, there was a significant difference with $\mathrm{p}=0.02$.

Data from a $2 \mathrm{~mm}$ thick specimen: Flexural Strength of Injection Mold was higher than CAD/CAM (Table 2) (Injection Mold: 77.3 MPa and CAD/CAM: 75.9 MPa). Further data analyses demonstrate that the difference between the two techniques is not statistically significant (Graph 2, Table 3).

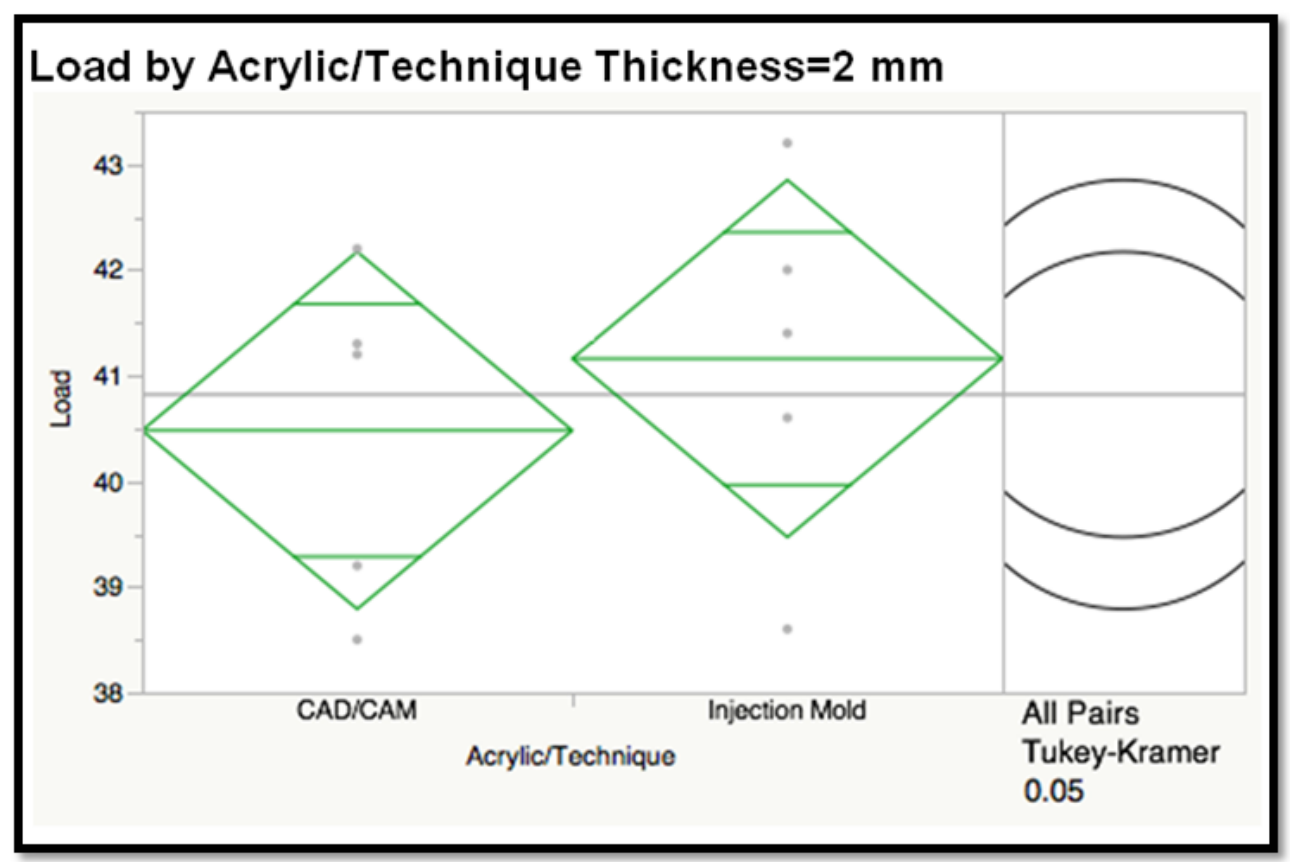

Graph 2: Tukey-Kramer Test comparison of $2 \mathrm{~mm}$ thick specimens by Injection Mold and CAD/CAM (Pressure-Packed specimen not included because they did not fracture) 


\section{LSD Threshold Matrix}

Abs (Dif)-HSD

\section{Injection CAD/CAM}

Mold

Injection

$-2.3909$

$-1.7109$

Mold

CAD/CAM $\quad-1.7109 \quad-2.3909$

Positive values show pairs of means that are significantly different.

Table 3: Least Significant Difference comparison test of Injection Mold and CAD/CAM techniques of $2 \mathrm{~mm}$ thick specimens

Data from a $3 \mathrm{~mm}$ thick specimen: Flexural strength of Injection Mold was the highest of the other two (Table 2) (Injection Mold: 88.8 MPa, CAD/CAM: 72.8 MPa, and Pressure-Pack: 65.3 MPa). Further data analyses demonstrate that the difference between Injection Mold and the other two techniques is statistically significant (Graph 3, Table 4). The p-Value is $<0.05$ when Injection mold is compared to the other two techniques (Table 5). Tukey-Kramer test, LSD test, and p-Value suggest that there is a difference between Pressure-Pack and CAD/CAM but it is not statistically significant (Graph 3, Table 4, Table 5). 


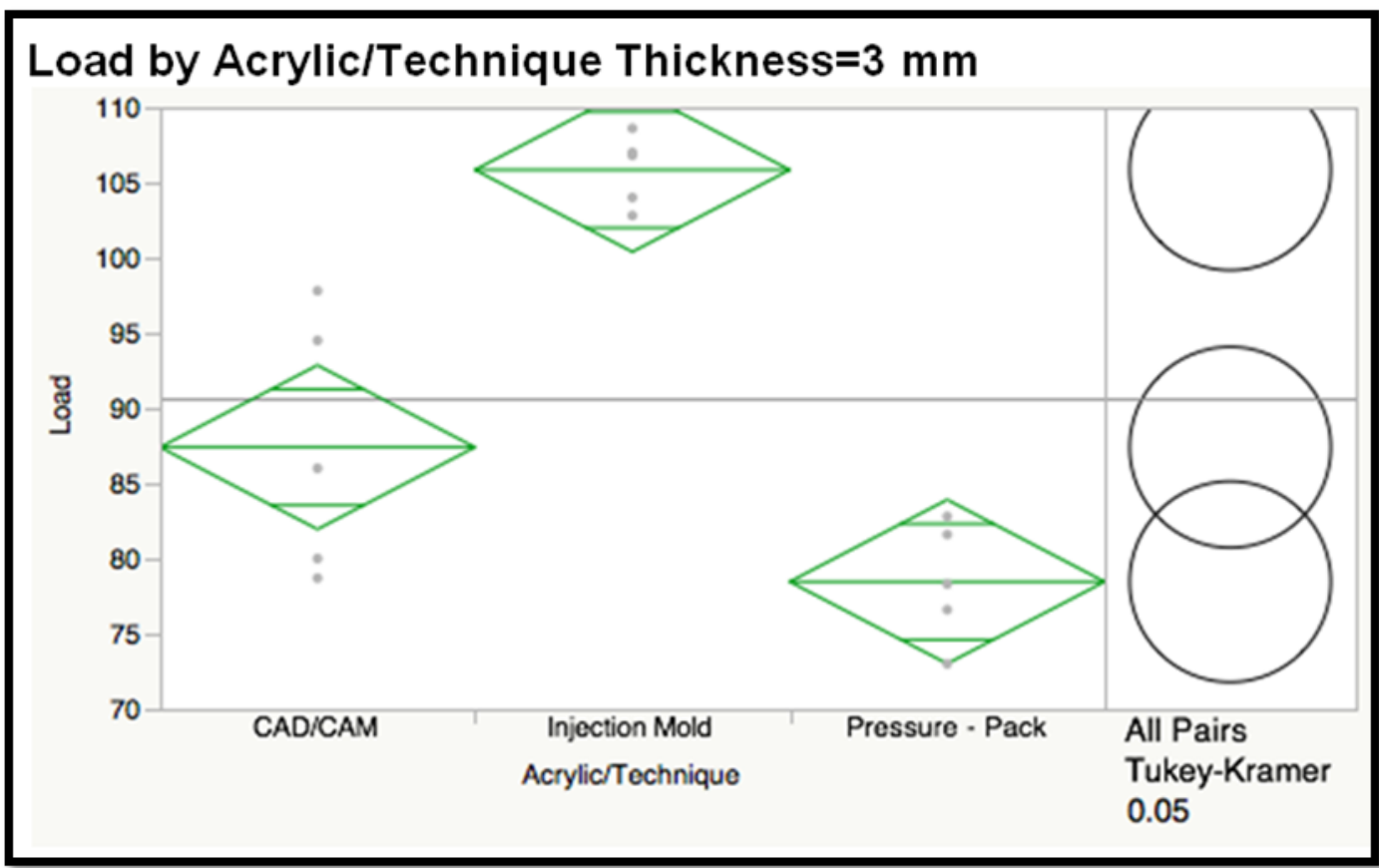

Graph 3: Tukey-Kramer Test comparison of $3 \mathrm{~mm}$ thick specimens prepared by Injection Mold, CAD/CAM, and Pressure-Pack techniques

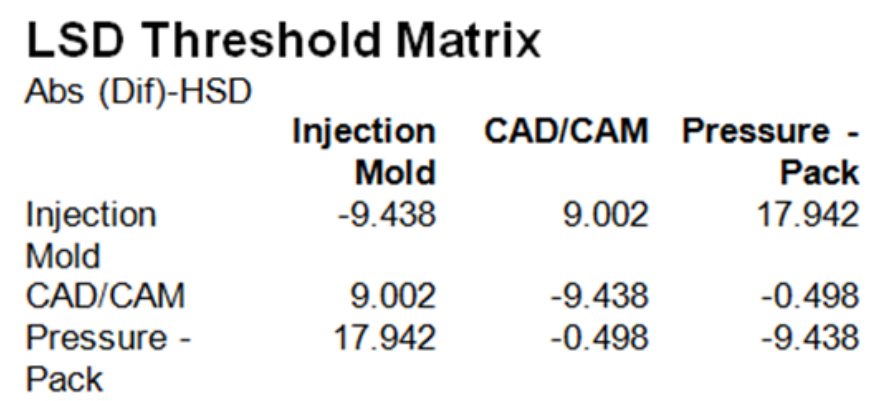

Positive values show pairs of means that are significantly different.

Table 4: Least Significant Difference comparison test of Injection Mold, CAD/CAM, and Pressure-Pack techniques of $3 \mathrm{~mm}$ thick specimens 


\section{Ordered Differences Report}

Level

- Level

Difference

Injection Mold Pressure - Pack

27.38000

Std Err Dif

Injection Mold

$\mathrm{CAD} / \mathrm{CAM}$

18.44000

3.537815

$\mathrm{CAD} / \mathrm{CAM}$

Pressure - Pack

8.94000

3.537815

Lower CL

Upper CL p-Value

17.9420

36.81803

$<.0001^{*}$

9.0020

27.87803

$0.0006^{*}$

3.537815

$-0.4980$

18.37803

0.0640

Table 5: Ordered Differences Report of $3 \mathrm{~mm}$ thick specimens prepared by all three techniques

Data from a $5 \mathrm{~mm}$ thick specimen: Flexural strength of Injection Mold was the highest of the other two (Table 2) (Injection Mold: 103.2 MPa, CAD/CAM: 90.8 MPa, and Pressure-Pack: 77.4 MPa). Further data analyses demonstrate that the difference between Injection Mold and Pressure-Pack technique is statistically significant (Graph 4, Table 6). The p-Value is $<0.05$ when Injection mold is compared to Pressure-Pack (Table 7). The p-Value is $<0.05$ when Injection mold is compared to Pressure-Pack (Table 7).

\section{Load by Acrylic/Technique Thickness $=5 \mathrm{~mm}$}

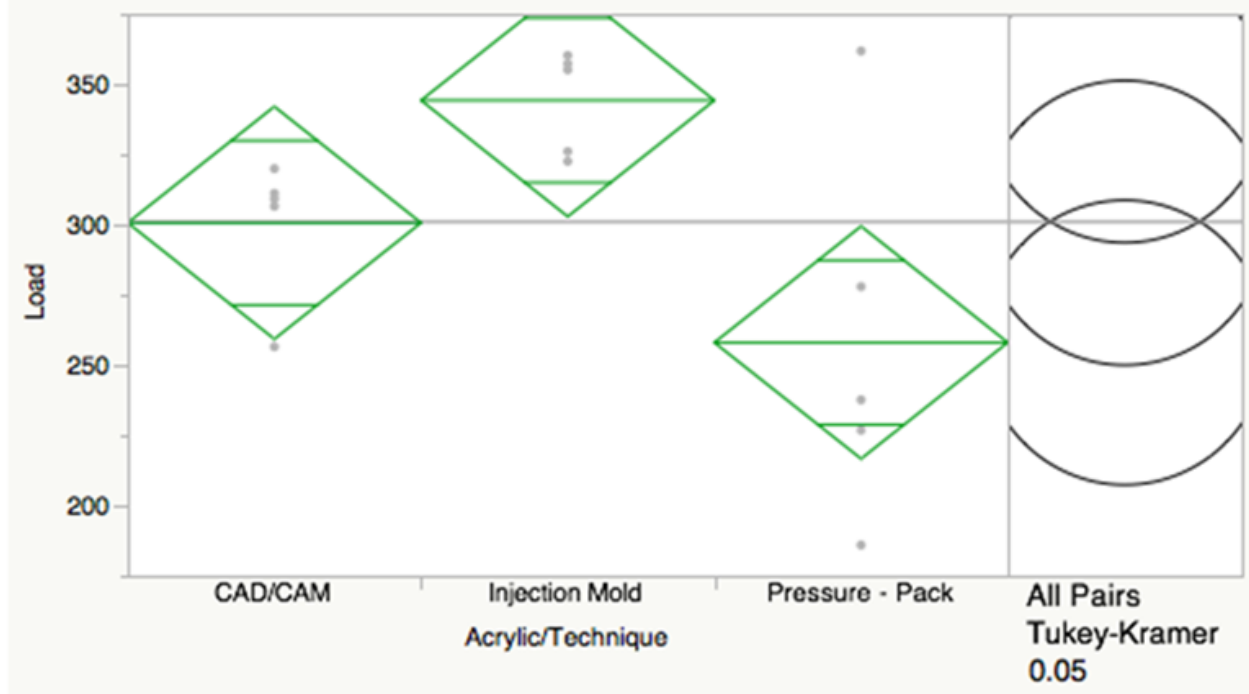

Graph 4: Tukey-Kramer Test comparison of $5 \mathrm{~mm}$ thick specimens prepared by Injection Mold, CAD/CAM, and Pressure-Pack techniques 


$\begin{array}{lrrr}\begin{array}{l}\text { LSD Threshold Matrix } \\ \text { Abs (Dif)-HSD }\end{array} & \begin{array}{r}\text { Injection } \\ \text { Mold }\end{array} & \text { CAD/CAM } & \begin{array}{r}\text { Pressure - } \\ \text { Pack }\end{array} \\ & -71.652 & -28.052 & 14.568 \\ \text { Injection } & & & \\ \text { Mold } & -28.052 & -71.652 & -29.032 \\ \text { CAD/CAM } & 14.568 & -29.032 & -71.652 \\ \begin{array}{l}\text { Pressure - } \\ \text { Pack }\end{array} & & & \end{array}$

Positive values show pairs of means that are significantly different.

Table 6: Least Significant Difference comparison test of Injection Mold, CAD/CAM, and Pressure-Pack techniques of $5 \mathrm{~mm}$ thick specimens

Ordered Differences Report

Level

Injection Mold

Injection Mold

$\mathrm{CAD} / \mathrm{CAM}$
- Level

Pressure - Pack

$\mathrm{CAD} / \mathrm{CAM}$

Pressure - Pack
Difference

86.22000

43.60000

42.62000
Std Err Dif 26.85865

26.85865

26.85865
Lower CL 14.5676 $-28.0524$

$-29.0324$
Upper CL 157.8724 115.2524 114.2724
p-Value $0.0190^{*}$

0.2739

0.2884

Table 7: Ordered Differences Report of $5 \mathrm{~mm}$ thick specimens prepared by all three techniques

\section{DISCUSSION}

The present study measured and compared the flexural strength of denture base acrylic resin processed by three different techniques: conventional Pressure-Pack (compression molded) method, Injection molded (SR-Ivocap), and CAD/CAM (AvaDent ${ }^{\mathrm{TM}}$ Digital Dentures). The null hypothesis that there would not be any statistically significant difference in the flexural strength of the three denture base processing technique was rejected. 
To reduce the incidence of fracture of denture bases, a good processing technique that reduces or eliminates residual stress within the denture and prevents surface defects is essential. Many authors stated that mechanical properties of PMMA varied depending on the polymerization technique (Nogeuira 1999, Raut 2013, Zappini 2003). The present study compared flexural strength of acrylic processed by three different polymerization techniques and included the variable of thickness.

When data from a $2 \mathrm{~mm}$ thick specimen is evaluated: Flexural Strength of Injection Mold was the highest. Data analyses demonstrate that the difference between the Injection Mold technique and CAD/CAM technique is not statistically significant. The Pressure-Packed specimens were not included in data analyses because they did not fracture and flexed past the limit of $15 \mathrm{~mm}$ displacement (Figure 12). This particular observation can be attributed to many things: The decreased amount of complete polymerization when Pressure-Pack technique is utilized may be a possibility, which can make the acrylic less brittle and more flexible (Gurbuz 2010). This particular experiment showed that there was tremendous flexure (Displacement $(\mathrm{mm})$ ) upon decreased Load $(\mathrm{N})$ in the $2 \mathrm{~mm}$ Pressure-Pack specimen. CAD/CAM acrylic is milled from a pre-polymerized block which makes it very strong and brittle especially at a lower thickness, as the data indicates. Injection Mold technique uses an Ivocap acrylic resin which differs in composition of PMMA constituents from Lucitone 199 and this can attribute to the polymerization difference (Table 1).

When data from a $3 \mathrm{~mm}$ thick specimen is evaluated: Flexural strength of Injection Mold was higher than both CAD/CAM and Pressure Packed acrylic. Data analyses demonstrate that the difference between Injection Mold and the other two techniques is statistically significant. That was difference between Pressure-Pack and CAD/CAM but it was not statistically 
significant. The $3 \mathrm{~mm}$ specimen data is very crucial because the width of the clinical denture border and flange is recommended to be a minimum of $2-3 \mathrm{~mm}$ (Zarb 2004). When considering the above mentioned data, processing the denture base with Injection Mold technique would provide the highest flexural strength.

When data from a $5 \mathrm{~mm}$ thick specimen is evaluated: Flexural strength of Injection Mold was highest. Data analyses demonstrate that the difference between Injection Mold and PressurePack technique is statistically significant. Moreover, Tukey-Kramer test, LSD test, and p-Value: there is a difference between Injection Mold and CAD/CAM but it is not statistically significant. There was a difference between Pressure-Pack and CAD/CAM but it was not statistically significant.

The results of this study are in agreement with a previous study performed by Raut in which Injection Mold technique prepared samples had a statistically significant higher flexural strength when compared with Pressure-Pack (Raut 2013). The flexural strength test is especially useful in comparing denture base materials in which stress of this type are applied to the denture during mastication (Wiskott 1995). The flexural strength is a combination of compressive, tensile, and shear strengths, all of which directly reflect the stiffness and resistance of material to fracture (Gorbuz 2010). The results from flexural test indicated that the differences observed can be attributed to the polymer constituents and to the method of polymerization (Raut 2013).

The reason for lower mean flexural strength for Pressure-Pack technique compared with other techniques might be due to presence of large number of porosities (Yannikakis 2002). It has been reported that porosity can weaken acrylic resin prosthesis (Yannikakis 2002). Porosity can also result in high internal stresses and vulnerability of denture base to distortion and 
warpage (Zappini 2003). It was concluded that since these specimen could not be kept under pressure during polymerization process, common defects and internal voids result (Yannikakis 2002, Zappini 2003).

It has already been reported that dentures processed by Pressure-Pack have increased dimensional change when compared with Injection Molded technique (Parvizi 2004). One other possible reason for Pressure-Pack specimens' lower flexural strength may be due to their preparation of manually mixing and packing making it difficult to obtain dense specimens (Raut 2013). Moreover, since there is a difference in acrylic (Ivocap with different constituents and CAD/CAM has pre-polymerized block of Lucitone 199) the influence on polymerization must play a role in creating different mechanical properties of PMMA when prepared by different polymerization method.

Limitations of the present study included the load-to-failure flexural strength test performed. This test has been demonstrated to not fully characterize the mechanical properties of denture base resin and may be of limited clinical significance (Wiskott 1995). Fatigue test would be more suitable to simulate the clinical failure mechanism (Wiskott 1995). Although in vitro tests may not always reflect intraoral conditions and be predictive of clinical performance, however they are valuable and can be applicable to clinical situations. Clinically, heavy masticatory forces, or a complete denture opposing natural dentition can be potential situations where Injection molded prosthesis would be more suitable than the other techniques to provide higher flexural strength (Raut 2013). According to ISO 1567, the minimum flexural strength of denture base materials of Type 1, Type 3, Type 4 and Type 5 (heat polymerized polymers, thermoplastic blank or powder, light polymerized materials and microwave polymerized materials, respectively) should not be less than $65 \mathrm{MPa}$ (ISO 1567 standards). All three 
polymerization techniques produced an acrylic resin specimen that had a flexural strength above $65 \mathrm{MPa}$ (Table 2). Based on flexural strength properties, Injection mold technique can be used to provide higher flexural strength however, the difference may not be of clinical significance.

Factors such as polymerization cycle, PMMA constituents, flexural strength, and its implications in microstructural morphology may contribute to the understanding of material failure (Beyli 1981).

\section{CHAPTER V}

\section{CONCLUSION}

This investigation evaluated the flexural strength between denture base materials processed by three different techniques: CAD/CAM, Injection Mold, and Pressure-Pack. Within the limitations of this study, it was concluded that:

- Statistically significant difference was found between flexural strength of acrylic processed by CAD/CAM and Injection Mold with Injection Mold technique being superior.

- $\quad$ SR-Ivocap $3 \mathrm{~mm}$ thick specimen showed flexural strength of $88.8 \mathrm{MPa}, \mathrm{CAD} / \mathrm{CAM} 3$ $\mathrm{mm}$ thick specimen showed flexural strength of $72.83 \mathrm{MPa}$, and Pressure-Pack $3 \mathrm{~mm}$ thick specimen showed flexural strength of 65.3 Mpa.

Based on flexural strength properties, SR-Ivocap Injection Molding may prove to be more advantageous than $\mathrm{CAD} / \mathrm{CAM}$ AvaDent ${ }^{\mathrm{TM}}$ and conventional Pressure-Pack.

Following designs of further studies are needed: 
Look at Scanning Electron Micrographs to analyze all the specimens and form a qualitative analysis of crack propagation, craze line initiation, and the nature of the specimen's fracture.

Vacumm mix the acrylic resin samples to diminish the number of porosities then perform the study.

An investigation of denture base resins processed by CAD/CAM, Injection mold, and Pressure Pack, by means of fatigue test could be of clinical significance. 


\section{$\underline{\text { References }}$}

Al-Rifaiy, M. Q. (2010). The effect of mechanical and chemical polishing techniques on the surface roughness of denture base acrylic resins. The Saudi Dental Journal, 22(1), 13-17.

American Society for Testing and Materials. (2005).

ASTM standard D790M for plastics. in: Annual book of ASTM standards ASTM

International, , 284-292.

Anderson, G. C., Schulte, J. K., \& Arnold, T. G. (1988). Dimensional stability of injection and conventional processing of denture base acrylic resin. Journal of Prosthetic Dentistry, 60, 394-398.

Artopoulos, A., Juszczyk, A. S., Rodriguez, J. M., Clark, R. K. F., \& Radford, D. R. (2013). Three-dimensional processing deformation of three denture base materials. The Journal of Prosthetic Dentistry, 110(6), 481-487.

AvaDent digital dentures; global dental science LLC.Available at: http://www.avadent.com

Baemmert, R. J., Lang, B. R., Barco, M. T. J., \& Billy, E. J. (1990). Effects of denture teeth on the dimensional accuracy of acrylic resin denture bases. International Journal of Prosthodontics, 3, 528-537.

Barsoum, W. M., Eder, J., \& Asgar, K. (1968). Evaluating the accuracy of fit of aluminum-cast denture bases and acrylic resin bases with a surface meter. Journal of American Dental Association, 76, 82-88.

Becker, C. M., Smith, D. E., \& Nicholls, J. I. (1977). The comparison of denture base processing techniques. part I. material characteristics. Journal of Prosthetic Dentistry, 37, 330-338.

Beyli, M. S., Dent, M. E., \& Fraunhofer, J. A. (1981). An analysis of causes of fracture of acrylic resin dentures. Journal of Prosthetic Dentistry, 46, 238-241.

Bidra, A., Taylor, T., \& Agar, J. (2013). Computer-aided technology for fabricating complete dentures: Systematic review of historical background, current status, and future perspectives. Journal of Prosthetic Dentistry, 109(6), 361-366.

Craig, R. G., \& Powers, J. M. (2002). Restorative dental materials (11th ed., pp. 636-689). St. Louis, MO: Mosby.

Dentca-CAD/CAM denture; dentca inc.Available at: http://www.dentca.com

Garfunkel, E. (1983). Evaluation of dimensional changes in complete dentures processed by injection-pressing and the pack-and-press technique. Journal of Prosthetic Dentistry, 50, 757-761. 
The glossary of prosthodontic terms.(2005). Journal of Prosthetic Dentistry, 94, 20-21.

Grunewald, A. H., Paffenbarger, G. C., \& Dickson, G. (1952). The effect of molding processes on some properties of denture resins. Journal of American Dental Association, 44, 269.

Gurbuz, O., Unalan, F., \& Dikbas, I. (2010). Comparison of the fracture resistance of six denture base acrylic resins. Ohdmbsc, 9, 21-24.

Hayakawa, I. (1999). Principles and practice of complete dentures (pp. 109). Tokyo: Quintessence Publishing Company.

International Standards Organization. ISO 1567 for denture base polymers. Geneva: ISO; 1998. Available from: http://www.iso.ch/iso/en/prodsservices/ISOstore/store.html.

Jadhav, R., Bhide, S. V., \& Prabhudesai, P. S. (2013). Assessment of the impact strength of the denture base resin polymerized by various processing techniques. Indian Journal of Dental Research, 24, 19-25.

Kanazawa, M., Inokoshi, M., Minakuchi, S., \& Ohbayashi, N. (2011). Trial of a CAD/CAM system for fabricating complete dentures. Dental Materials Journal, 30, 93-96.

Kattadiyil, M. T., Goodacre, C. J., \& Baba, N. Z. (2013). CAD/CAM complete dentures: A review of two commercial fabrication systems. Journal of the California Dental Association, 41(6), 407-416.

Kawahata, N., Ono, H., Nishi, Y., Hamano, T., \& Nagaoka, E. (1997). Trial of duplication procedure for complete dentures by CAD/CAM. Journal of Oral Rehabilitation, 24, 540548.

Keenan, P. L. J., Radford, D. R., \& Clark, R. K. F. (2003). Dimensional change in complete dentures fabricated by injection molding and microwave processing. The Journal of Prosthetic Dentistry, 89(1), 37-44.

Kuhar, M., \& Funduk, N. (2005). Effects of polishing techniques on the surface roughness of acrylic denture base resins. The Journal of Prosthetic Dentistry, 93(1), 76-85.

Machado, C., Sanchez, E., Azer, S. S., \& Uribe, J. M. (2007). Comparative study of the transverse strength of three denture base materials. Journal of Prosthetic Dentistry, 35, 930933.

Maeda, Y., Minoura, M., Tsutsumi, S., Okada, M., \& Nokubi, T. (1994). A CAD/CAM system for removable denture. part I: Fabrication of complete dentures. International Journal of Prosthodontics, 7, 17-21. 
Mang, T. R. J., \& Latta, M. A. (2005).

Physical properties of four acrylic denture base resins Journal of Contemporary Dental Practice, 15(6), 93 - 100.

Matthews, E., \& Smith, D. C. (1955). Nylonas a denture base material. British Dental Journal, 98, 231-237.

Miyazaki, T., Hotta, Y., Kunii, J., Kuriyama, S., \& Tamaki, Y. (2009).

A review of dental CAD/CAM: Current status and future perspectives from 20 years of experience. Journal of Dental Materials, 28, 44-56.

Munoz, C. (2013).

Evaluation of the properties of AvaDent processed denture material Dental Biomaterials Research Laboratory,

Negreiros, W. A., Consani, R. L., Verde, M. A., Silva, A. M., \& Pinto, L. P. (2009). The role of polymerization cycle and post-pressing time on tooth movement in complete dentures.

Brazil Oral Research, 23(4), 467-472.

Nogueira, S. S., Ogle, R. E., \& Davis, E. L. (1999). Comparison of accuracy between compression- and injection-molded complete dentures. The Journal of Prosthetic Dentistry, 82(3), 291-300.

Parvizi, A., Lindquist, T., Schneider, R., Williamson, D., Boyer, D., \& Dawson, D. V. (2004). Comparison of the dimensional accuracy of injection-molded denture base materials to that of conventional pressure-pack acrylic resin. Journal of Prosthodontics, 13(2), 83-89. doi:10.1111/j.1532-849X.2004.04014.x

Pryor, W. J. (1942). Injection molding of plastics for dentures. Journal of American Dental Association, 29, 1400-1408.

Raut, A., \& Polsani, L. R. (2013). An in vitro study to compare the transverse strength of thermopressed and conventional compression-molded polymethylmethacrylate polymers. Indian Journal of Dental Research, 24(3), 356-362.

Salloum, A. M. (2013). Influence of high expansion dental stone used as investing medium on the changes in occlusal vertical dimension of complete dentures. The Saudi Dental Journal, 25(4), 135-140.

Skinner, E. W., \& Cooper, E. M. (1943). Physical properties of denture resins: Part I. curing shrinkage and water sorption. Journal of American Dental Association, 30, 1845-1852.

Strohaver, R. A. (1989). Comparison of changes in vertical dimension between compression and injection molded complete dentures. The Journal of Prosthetic Dentistry, 62(6), 716-718. 
Sykora, O., \& Sutow, E. J. (1990). Comparison of the dimensional stability of two waxes and two acrylic resin processing techniques in the production of complete dentures. Journal of Oral Rehabilitation, 17(219-227)

Takamata, T., Setcos, J. C., Phillips, R. W., \& Boone, M. E. (1989). Adaptation of acrylic resin dentures as influenced by the activation mode of polymerization. Journal of American Dental Association, 1(19), 271-276.

Wall, D. M. (1955). Clinical assessment of nylon as a denture base material. British Dental Journal, 98, 238-241.

Wiskott, H. W., Nicholls, J. I., \& Belser, U. C. (1995). Stress fatigue: Basic principles and prosthodontic implications. International Journal of Prosthodontics, 8, 105-116.

Woelfel, J. B., \& Paffenbarger, G. C. (1959). Dimensional changes occuring in artifical dentures. International Dental Journal, 9, 451-460.

Woelfel, J. B., Paffenbarger, G. C., \& Sweeney, W. T. (1960). Dimensional changes occurring in dentures during processing. Journal of American Dental Association, 61, 413-430.

Yannikakis, S., Zissis, A., Polyzois, G., \& Andreopoulos, A. (2002). Evaluation of porosity in microwave-processed acrylic resin using a photographic method. The Journal of Prosthetic Dentistry, 87(6), 613-619.

Zakhari, K. N. (1976). Relationship of investing medium to occlusal changes and vertical opening during denture construction. The Journal of Prosthetic Dentistry, 36(5), 501-509.

Zappini, G., Kammann, A., \& Wachter, W. (2003). Comparison of fracture tests of denture base materials. The Journal of Prosthetic Dentistry, 90(6), 578-585.

Zarb, G., Bolender, C., Eckert, S., Jacob, R., Fenton, A., \& MericskeStern, R. (2004). Prosthodontic treatment for edentulous patients (12th ed.). St. Louis, MO: Mosby. 